\title{
EL LATÍN EN LA MÚSICA
}

\section{Manuel Antonio Quirós R.}

\begin{abstract}
This paper focuses on the fundamental role played by the latin language for the theory, terminology, texts and works in the music history of the western civilization, from the Ambrosian Hymnology to the genial composers pertaining to several music periods.
\end{abstract}

\section{Introducción: relaciones entre el latín y la música}

El latín es uno de los idiomas que más uso ha tenido en la historia de la música occidental, por los siguientes aspectos:

1. En la época clásica de la literatura latina, empleo de coros en el teatro romano.

2. En él se sistematizó, sobre la base de la teoría musical griega, la teoría musical del Occidente, enseñada en el Quadrivium del Studium Generale.

3. Fundamentada en tal teoría, se llevó a cabo, en las catedrales, la práctica musical del Canto Gregoriano, siempre íntimamente asociado con el latín.

4. Composición de una inmensa cantidad de géneros musicales con textos en latín, casi siempre de corte religioso( monódico, o polifónico) en donde sobresalen las misas, muchas de las cuales de óptima calidad musical.

5. Nombres en latín de las notas musicales:

$$
\text { ut (do), re, mi, fa, sol, la, si, }
$$

en los territorios de lenguas romances: Italia, Francia, España...,

6. Uso del alfabeto latino:

$$
\begin{aligned}
& \mathbf{A}=\mathbf{l a} ; \mathbf{B}=\text { si bemol, en alemán, y si, en inglés; } \mathbf{C}=\mathbf{d o} ; \mathbf{D}=\mathbf{r e} ; \mathbf{E}=\mathbf{m i} ; \mathbf{F}=\mathbf{f a} ; \\
& \mathbf{G}=\text { sol } \mathbf{y} \mathbf{H}=\mathbf{s i} \text {. }
\end{aligned}
$$

en los territorios de lenguas germánicas: Alemania, Austria, Inglaterra... 
7. Denominaciones, en dicho idioma, de excelentes ensembles musicales:

Amadeus, Capella Coloniensis, Collegium Aureum, Collegium Musicum, Concentus Musicus, Schola Cantorum Basiliensis...

8. Latinismos de la música:

ad libitum, comes, Manus guidiana, missa solemnis, Ars Antiqua, Ars Nova, cantus firmus, Carmina Burana, opus, schola cantorum. ictus, Te Deum, Dies irae...

9. Cultismos musicales en italiano, idioma de procedencia latina.

El presente trabajo enfatiza las relaciones del latín con la música y la importancia que ha desempeñado tal lengua en tal arte.

(Para fines de presentación, siempre que aparezca un latinismo: cualquier palabra, frase o texto en latín, será destacado en letra negrita).

\section{Historia de tales relaciones}

\section{En la literatura clásica del latín}

Las relaciones del latín con la música se iniciaron desde la misma literatura clásica, principalmente, durante las actuaciones del coro en representaciones de obras teatrales. Pero, como no se posee casi nada de documentación, sólo esbozo algunos aspectos del uso del latín en la música luego de la aparición del Cristianismo.

\section{En el cristianismo primigenio}

En los templos de los primeros cristianos se entonan salmos bíblicos y preces de alabanza y de fe.

En una especie de segunda Romanización, del legado de la Roma Clásica, la Iglesia sigue transmitiendo con mentalidad cristiana lo que le era ventajoso para su evangelización; en tal legado va inmerso el mismo latín. ...Éste se constituye en lengua de culto a partir del papa Víctor I, la cual, desde el siglo IV penetra, definitivamente, en la liturgia de la Iglesia de Roma, en sustitución del griego, una vez que la situación política de tal institución, cambia por mérito del emperador Constantino (272-337).

En los evangelios, aparece el Hymnus Angelicus: el Gloria in excelsis Deo..., que se ha prestado para el cántico de alabanza en la misa.

Antes del año 100, el apóstol Pablo, para contrarrestar el mundo pagano, recomienda en Éfesos y en Colosenses, el canto: salmos, himnos y canciones piadosas, simplememte, entonar lo que se reza sobre todo, el Pater noster... pero, de ninguna manera presentar ofrendas en los altares con bombos, címbalos, flautas ni otros instrmentos de tonos estúpidos, pues esto lo hacen sólo los paganos. 
Luego de la sustitución del griego por el latín en la Iglesia de Roma, tales preces son entonadas en este idioma. Y, para fines del culto litúrgico, a partir de la teoría musical del griego, paulatinamente se fue elaborando, en latín, la teoría músical. La necesidad de retener de memoria las melodías, creó una simbología musical sobre la base del alfabeto, primero griego, luego latino.

El Concilio de Laodicea (367) estipuló el canto litúrgico ejecutado sólo por cantores con voz educada y organizados en corales: las futuras scholae cantorum.

\section{El Cantus Ambrosianus y su latín}

San Ambrosio (340-397) continuó el camino que había trazado el Concilio de Laodicea, para ello se fundamentó en la himnología de Antioquía: un canto antifonal salmódico (en griego), que, ya había sido entonado en Jerusalem.

En 386 comienzan a aparecer y a entonarse, en Milán, los himnos: un canto distinto del de Roma; es el himno métrico latino ambrosiano; palabras musicalizadas según la fórmula rítmica del tetrámetro yámbico:

\section{Aeterne rerum conditor... \\ Deus creator omnium... \\ Iam surgit hora tertia... \\ Veni redemptor gentium...}

Y el himno atribuido a San Ambrosio:

\section{Te Deum laudamus}

\section{Te Dominum confitemur}

Te aeternum Patrem

omnis terra veneratur.

Tibi omnes angeli,

\section{tibi caeli et universae potestates...,}

que ha sido, además de en Gregoriano, musicalizado por grandes compositores, como el austríaco, J. Haydn.

Los himnos de San Ambrosio suponen un cabal conocimiento de la gramática y estilos clásicos, además, de una capacidad semántica para adaptar el pensamiento pagano encerrado, en el latín, a la nueva mentalidad cristiana.

La manera ambrosiana se expandió por la cristiandad con el patrón dictado por el santo milanés, cuyos cambios, en el campo literario-musical, impresionaron a sus contemporáneos; algunos hasta fueron introducidos en la Iglesia de Roma durante el Papa Celestino I (422-432). Se da en San Ambrosio una simbiosis entre poesía y música, y por razones de las relaciones del latín con otras lenguas, se origina el acento de espiratorio, propio de las lenguas romances en contraposición con el acento musical latino clásico de vocales breves y largas. 
Creación de otros himnos en latín

Existen muchos otros himnos escritos en los primeros siglos del Cristianismo, durante la Edad Media y en el Renacimiento. De ellos entresaco:

Beate pastor, Petre, clemens accipe...

Egregie doctor, Paule, mores instrue...

Opes decusque regium reliqueras...

Salutis humanae sator...

Vexilla regis...,

de Venancio Fortunato, el poeta de la Dulcedo.

Veni, Creator Spiritus...,

atribuido a Rábano Mauro.

O gloriosa virginum...

Lustra sex qui iam peregit...

Ira iusta Conditoris...

O quot undis lacrimarum...

Ave, maris stella...,

$\tan$ musicalizado posteriormente: Josquin des Pres,

Claudio Monteverdi, entre otros.

Christe sanctorum decus angelorum...

Sacra iam splendent decorata lychnis...

Ut queant laxis resonare fibris...,

el himno del que fueron tomados los nombres de las notas musicales en las lenguas romances, cuyo autor literario es Paolo Diácono, del Círculo Carolingio.

Iste confessor Domini colentes...

Iam toto subitus vesper eat polo...

Custodes hominum psallimus angelos...

Sanctorum meritis inclyta gaudia...

Regali solio fortis Iberiae...

Fortis, inopsque Deo...

Servire, regno praetulit...

Estos fueron escritos por Tomás de Aquino:

Adoro te devote, latens Deitas...

Pange, lingua, gloriosi, Corporis mysterium...

Sacris solemniis... 
Los himnos de la Edad Media poseen una acentuación románica, y los del Renacimiento, es obvio, imitan el ritmo clásico.

En el siglo V., el canto antifonal-responsorial llega a Roma (en donde es puesto en práctica por el Papa Celestino (422-432), Benevento y Montecasino, sitio de fundación de la Orden Benedictina, la cual estipuló, entre sus actividades, el estudio y la práctica del canto litúrgico y de la cual procedieron grandes teóricos de la música.

\section{Primeros tratadistas, en latín, de la música}

Los primeros teóricos de la música escribieron sus obras en latín a caballo entre la Edad Antigua y la Edad Media. Por razones de espacio sólo menciono a tres de ellos:

Entre San Ambrosio y Gregorio Magno les tocó pasar por este mundo al autor del De civitate Dei, San Agustín. En sus Confessiones (X, 33), el santo de Hipona escribe sobre la emoción que causa el arte musical. San Agustín escribió De musica libri VI; al autor de la Consolatio philosophiae, Boecio Severino, excanciller de Teodorico, quien, sobre la base de los antiguos modos griegos, agregados a la escala musical latina, coloca los cimientos de la música posterior, con lo cual se constituye, por más de 1000 años, en una fuente imprescindible de la erudición musical, al menos con su libro De musica. Magno Aurelio Casiodoro, en su convento del sur de Italia, redactó unas Institutiones musicae, parte integrante del De artibus ac disciplinis liberalium litterarum.

\section{El cantus firmus in latina lingua}

El Canto Gregoriano, denominado también Cantus Planus y Cantus Firmus es una música espiritual, sacro-ritual, llana, simple, monódico-diatónica y tradicional, siempre con un texto en latín, ejecutada sin acompañamiento de instrumentos y confiada a una schola cantorum: un coro especializado, generalmente, compuesto por voces masculinas.

Antes de que el Papa Gregorio Magno (590-604)se interesara por codificar el canto que lleva su nombre, ya existía bastante material de donde echar mano: la música griega antigua y bizantina, la alejandrina, la judía, la auctóctona romana y diversos elementos traídos de otras partes del mundo en donde Roma era la dueña y señora.

El Gregoriano no sólo posee valor en sí mismo: canto litúrgico oficial de la Iglesia de Roma, sino también por los frutos que le ha proporcionado a la futura música del Occidente, incluso seglar, en donde el latín seguirá estando íntimamente ligado con la polifonía posterior a él.

Cuando se comenzó a formular y sistematizar el Cantus Firmus ya el latín era de amplio uso en las ceremonias litúrgicas de la Iglesia de Roma, pues, por ahí de los siglos V y VI, las lenguas modernas, tanto románicas como germánicas, apenas están en el inicio de su formación como idiomas. El latín sigue siendo la lengua del culto y de la cultura escolar y escrita. Se cantaban textos sagrados, que, reunidos en un corpus, 
ambos, música e idioma, constituyen la unidad del canto: ¡no hay Gregoriano si el texto no está en latín!, texto que, a la postre, es creación de la Edad Media, pero cuyos autores, por el estudio de la gramática, tenían como modelos a los Auctores de la antigüedad clásica.

El Cantus Planus es la consecuencia de la preocupación recopiladora y sistematizadora del Servus servorum Dei (como solía llamarse a sí mismo San Gregorio) por dotar a la Iglesia de unidad y universalidad: unidad y universalidad religiosa, musical y lingüística.

Para obtener resultados, Gregorio Magno llevó a cabo un ordenamiento de lo hasta entonces existente: una codificaciión como embrión musical, que fructificó en lo siguiente:

1. Creación de un canto antifonal (dos coros que se responden mútuamente).

2. Recolección y organización de un "repertoire" en un canto sin ninguna arbitrariedad personal por parte de los ejecutantes.

3. Establecimiento provisional de la missa en ordinarium y porprium.

4. Creación del officium u horas canónicas.

5. Fundación de las scholae cantorum.

6. Unidad entre el culto y sus melodías, entre la música y el texto latino: melodías exclusivamente litúrgicas, sencillas pero sinceras: el antiphonarium.

Gran parte de la labor del Papa se llevó a cabo en la Urbs y en el Monasterio de Montecasino, cuyos monjes, cumpliendo con su lema de Ora et labora lo secundaron en su trabajo, máxime que él había sido un producto de la Ordo Benedictina.

\section{Difusión transalpina del Canto Gregoriano e importancia para la música polifónica}

Por la difusión del Canto Gregoriano allende los Alpes, siguendo los dictados del mismo Gregorio en pro de la predicación del Evangelio, su música se difunde fuera de Italia, país de más fácil control papal; no falta quien lo lleva a Suiza (Monasterio de San Galo); otros lo llevan a Francia (San Marcial de Limoges y Rouen); alguien lo incorpora en Aquisgrán, el centro del Renacimiento Carolingio, en cuyas escuelas la música formará parte del Quadrivium. En Aquisgrán ya existía un órgano y se funda una schola cantorum. San Augustín (597) lo lleva a Inglaterra (Canterbury y York), San Bonifacio (700) a Alemania (Metz y Reichenau), San Ildelfonso (700) a España. La música, junto con el latín, en una especie de nueva romanización y latinización, extienden la cultura de la Nova Roma bajo el Signum Crucis.

Además de su importancia interna y de constituir la música oficial de la Iglesia Católica Romana, el Canto Gregoriano posee valor, luego de su europeización por las siguientes razones:

1. Su íntima unión con el latín, uno de los grandes idiomas de la cultura occidental, si no el principal. 
2. La necesidad de la retentiva memorística, para el momento del culto, acarreó la necesidad de inventar una especie de escritura musical, principio de la del Occidente.

3. Para su ejecución, la creación de las scholae cantorum.

4. Su sobrevivencia en la música polifónica y contrapuntística posterior en: temas, melodías de base, el tenor, repeticiones, introducciones, variaciones, reelaboraciones, imitaciones...

5. En él se fundamentan el organum, el contrapunctum, el conductus, el motetus las sequentiae, los tropoi y muchos géneros musicales, iniciados, de primero en el Canto Llano, principalmente, las missae.

6. Del Canto Gregoriano se originan las primeras escuelas musicales: la música de los trovadores provenzales, la música gótica de Notre Dame, el Ars Antiqua y el Ars Nova.

7. Y su permanencia, con altibajos, en el transcurso de los siglos, hasta el presente.

\section{La Solmisatio, el Hexacordium, la Manus Guidiana y el Ut queant...}

Gregorio el Grande hizo que su Cantus Firmus se extendiera fuera de su Roma, e incluso, transpasara los Alpes, lo cual le proporcionó, sin la tutela pontificia, un mayor desenvolmiento.

La necesidad de los cantores de disponer de un material para leer las notas, impulsó a la más grande innovación musical, posterior al Canto Gregoriano original, y de vigencia en la actualidad; es la labor del monje benedictino (del Monasterio de Pomposa, en las cercanías de Ravena) Guido de Arezzo (ca. 980-1050) quien, sobre la base del hexacordio, instrumento de seis notas, inventó la Solmisatio: sol, mi... (las dos notas extremas de tal instrumento); hizo uso de su mano, la Manus Guidiana como primer ejemplo de escritura de notas para ayuda visual y memorística, sobre todo, en lo referente a la altura de las notas, a las que les dio nombre a partir de un himno latino escrito en honor a San Juan Bautista por Paolo Diácono. El inicio de cada verso indica los nombres de las notas musicales, que, lingüísticamente, son latinismos en las lenguas modernas:

\section{UT (DO) queant laxis \\ REsonare fibris, \\ MIra gestorum \\ FAmulorum tuorum. \\ SOLve poluti \\ LAbii impii, \\ Sancte Iohannes.}

Notker Babulus y las sequentiae. Los tropoi, el motetus y los Carmina Burana 
Entre Guido de Arezzo y la música polifónica se crearon nuevas composiciones gregorianas: nacen en monasterios, alejados no sólo de Roma, sino hasta de Italia; entre otras, las sequentiae y los tropoi. Las primeras como ampliaciones, y las segundas, como intercalaciones del texto latino.

El inicio de tales innovaciones se dio con las sequentiae (del participio presente, neutro plural de sequens, sequentis; sequentia, 'secuencia, continuación', del verbo sequor, 'seguir') creadas por Notker Babulus, monje del monasterio de San Galo, y los tropoi, 'invenciones', de donde tropare 'trovar, encontrar', como intercalaciones en el texto gregoriano. Estas composiciones musicales, presentadas en forma de verso, fueron bastante cultivadas en el Monasterio de San Marcial de Limoges durante el siglo XI.

Constituyen las sequentiae una forma tardía del Canto Gregoriano (siglo X al XIII), elaboraciones poético-musicales bastante amplias, que se suelen recitar, o cantar luego del alleluya, para que se evite la repetición exagerada de la última -a: (alleluiaaaaaaaaa...), en la parte conclusiva del texto gregoriano. A tal fin, se echó mano de textos tradicionales, o se inventaron otros, que, generalmente, todavía se cantan en determinadas fiestas religiosas.

\section{Las más importantes secuencias en latín}

Las secuencias de mayor realce son:

\section{Victimae paschali laudes...,}

compuesta en el siglo XI por Vipón de Borgoña para celebrar la resurrección de Jesucristo.

\section{Veni Sancte Spiritus...,}

atribuida al Papa Inocencio III, quien la escribiera en 1100. (No confundirla con el himno Veni, Creator Spiritus...) .

Dies irae, dies illae...,

poetizada por Tomasso da Celano alrededor de 1250.

\section{Lauda Sion Salvatorem...,}

de Santo Tomás de Aquino (1227-1241) para que se recite o cante en la festividad del Corpus Christi. 
de Iacopone di Todi, creada tres años antes de su muerte (1306), pero que no fue aceptada por la liturgia católica hasta el siglo XVIII. Es una secuencia creada pensando en los Siete dolores de la Madre de Jesús al pie del Madero de la Cruz.

(De secuencias musicalizadas, la mejor es la del compositor, decedido muy joven, G. B. Pergolesi (1710-1736).

\section{Urbs aquensis,}

en Gregoriano del siglo XII, elaborada para celebrar la fiesta del Carlomagno, en Aquisgrán, muerto en enero del 814:

\section{Urbs aquensis, urbs regalis regni sedes principalis prima regum curia: \\ Regi regum pange laudes, quae de magni regis gaudes, Caroli praesentia.}

Por posible imitación o reminiscencia de la secuencia latina, se crearon también secuencias en romance, como la Cantilena de Santa Eulalia, en francés antiguo, cuya sustancia está tomada del correspondiente himno latino escrito por Prudencio, poeta cristiano nacido en Mérida, España y muerto en 304 como víctima de Dioclesiano:

1. Inicio de la secuencia latina:

\section{Cantica virginis Aulaliae \\ Concine suavisona cithara,}

Est operae quoniam pretium

Clangere carmine martyrium:

Tuam ego voce sequar melodiam

Atque laudem imitabor Ambrosiam...

2. Inicio de la secuencia románica:

Buona pulcella fut Eulalia.

Bel auret corps bellezour anima.

Uoldrent la ueintre li Deo inimi,

Uoldrent la faire diaule seruir... 
Los tropoi son adiciones, interpolaciones o ampliaciones al canto litúrgico, realizadas de una forma diplomática (como para que no se den cuenta), contra la fijación incambiable de la música sacra monódica. En este sentido, resulta una práfrasis de la melodía precedente por su introducción, intercalación o apéndice, la cual fue agradada a la liturgia a finales de la época carolingia.

Del tropus se genera el drama litúrgico, como en:

\section{Hodie cantandus est nobis...,}

tropus de Navidad, y

\section{Quem quaeritis...,}

tropus de la Resurrección.

De Teodulfo, el mejor poeta de Renacimiento Carolingio, procede el Gloria laus, en dísticos, cantado el Domingo de Ramos, después de los cuales siempre se repite el estribillo:

\section{Gloria, laus et honor tibi sit Rex Christe, Redemptor...}

El motetus 'motete', 'palabrita'(de la misma raíz que la palabra mot en francés, es una melodía litúrgica cantada en latín por el tenor, quien es acompañado por otras voces con textos diferentes, incluso, en lenguas distintas del latín, por lo cual vale la pena analizar, aunque sólo sea etimolgicamente, la palabra, originada en el verbo tenere, 'sostener, mantener': 'el que lleva o sostiene la melodía principal' (en Gregoriano y en latín) concomitantemente a otra melodía extraña y en romance. El tenor, en el inicio de la polifonía, lleva la melodía base (quia vocem tenebat) en la elaboración de un contrapunto (punctum contra punctum): 'nota sobre nota', que bien podía ser una melodía gregoriana preexistente (de donde, cantus firmus) o ser inventada por el nuevo compositor. El primer motetus data del 1100 y es el más antiguo tipo de polifonía.

Pero el motetus, el organum y el contrapunctum, que constituyen el origen de la polifonía, ya no pertenecen al Canto gregorino, sino al

\section{Período de Notre Dame o Gótico (1160-1250)}

Del Monasterio de San Marcial de Limoges, en los dominios del occitano (provenzal antiguo), o desde Aix-la-Chapelle (Aquisgrán) a Notre Dame de Paris no es muy lejos la distancia. En París aparecen las primeras escuelas musicales que se van distan- 
ciando del Gregoriano: la primera se donomina así, pues corresponde a la época de edificación de las catedrales medievales o catedrales góticas, principalmente, la de Notre Dame. Sobre la base del organum (el cual insinúa la idea de dos o más voces simultáneas, según se acorda el instrumento musical, este período musical constituye el paso o puente del canto monódico-coral al canto contrapuntístico-polifónico. Además de escribirse tal clase de música en la Catedral de Paris, se hace también en la Abadía de San Marcial de Limoges, importante centro creador de tropoi.

Los dos primeros representantes son el Magister Leoninus, un optimus organista quien escribió el Magnus liber organi de graduali et antiphonario pro servitio divino multiplicando y Perotinus. Ambos compusieron, en forma separada, un Viderunt omnes... a dos y a cuatro voces, respectivamente.

Por otro lado, en tierras sureñas de Francia, en los dominios de la Lengua de Oc, por ahí de los siglos XI y XII, la música sale de los templos y se comienza a hacer laica; se canta en las nacientes lenguas derivadas del latín vulgar: las cansós, en Provenza; las cantigas, en España; le laude, en Italia y hasta los Minnesänger, en Alemania, además de cantarse en latín culto, los

\section{Carmina Burana y el Gaudeamus igitur}

Del Renacimiento de los siglos XI, XII y XIII son los cantos goliardos, producto de los cuales es el himno de las universidades, el Gaudeamus igitur!. Es un florecimiento de la literatura latina medieval y el nacimiento de la literatura en romance. Los Carmina Burana son la mejor cosecha literaria del latín medieval por obra de poetas anónimos: en el marco de una poesía a la que no le interesan las alabanzas cristianas ni ultraterrenas, se pone en marcha un movimiento literario por parte de jóvenes estudiantes vagabundos: los goliardas; alegres y descontentos con sus suerte, cantan la naturaleza, el amor, el vino; el disfrute de sus años juveniles; critican ásperamente a la Iglesia y a sus representantes y tienen una actitud pesimista y paganizante ante la vida: la rueda de la Fortuna es la emperatriz del mundo, pues todo lo gobierna; se es juguete del hado, uno, montado sobre una rueda girante y cambiante, como la Fortuna, contra la cual el pobre y desvalido ser humano no puede hacer nada; por eso se lloran las heridas del triste hado: ¡cuidado los que hoy están arriba! Bien podría sucederles que mañana no lo estén, a modo de la pobre Hécuba, esposa de Priamo, quien, en la Guerra de Troya perdió a su amado esposo y a casi todos sus hijos:

\section{O Fortuna, velut luna statu variabilis, semper crescis}




\author{
aud decrescis; \\ vita detestabilis \\ tun obdurat \\ et tunc curat \\ ludo mentis aciem \\ egestatem \\ potestatem \\ dissolvit ut glaciem...
}

Así reza el inicio de los Carmina Burana al menos en el texto musicalizado por Karl Orff en este siglo.

En un latín literario y paganizante, se expresa la inmensa soledad, tristeza y pesimismo del ser humano dejado solo en el planeta a merced de la Fortuna.

Con un Gaudeamus igitur... empieza el himno de los estudiantes, el cual posee el mismo corte de los anteriores: disfrute de la juventud y de la vida, pues luego nos tragará la tierra, y actitudes pesimistas.

Tal himno es una de las tantas canciones estudiantiles, cuya tradición se remonta a los siglos XI y XII, los mismos que vieron nacer las universidades. Los Carmina Burana son del siglo XIII.

Habiendo sido creadas las universidades en la Edad Media, cuando el idioma de la vida docente-discente era el latín, consiguientemente, el himno universitario debía estarlo también en latín:

Gaudeamus igitur, iuvenes dum sumus!

(Bis).

Post iucundam iuventutem, post molestam senectutem, nos habebit humus, nos habebit humus.

Ubi sunt qui ante nos in mundo fuere?

(Bis).

Vadite ad superos, transite ad inferos, ubi iam fuere, ubi iam fuere. 


\section{Vivat Academia, vivant professores \\ (Bis). \\ Viva membrum \\ quodlibet, vivant membra \\ quaelibet, semper sint in flore, semper sint in flore! \\ Gaudeamus igitur, iuvenes dum sumus!}

(Bis).

También en Notre Dame aparecen otras escuelas musicales: el

\section{Ars Antiqua y el Ars Nova}

Estas dos escuelas componen y cantan tanto en latín como en romance. Dados los diferentes registros del organum y de las voces de las scholae cantorum, la música (el Canto Gregoriano), de monódica pasa a ser polifónica: aparecen el contrapunctum: la combinación de dos o más melodías en un mismo texto musical, o sea, la polifonía, aunque, es evidente, en forma rudimentaria.

Ambas escuelas también se originaron a orillas del sena, en Notre Dame. La primera (ca. de 1250-1320) con obras anónimas en latín: Amor potest..., In mari miseriae... y $\mathbf{O}$ mitissime... y algunas en francés antiguo.

En los siglos XI y XII, se iba gestando, cerca de Notre Dame, el Studium Generale (la Universidad) de París, en donde la música se sigue estudiando en forma teórica en el quadrivium; en las catedrales más bien se aprendía la ejecución musical.

En contraposición al Ars Antiqua, Phillipe de Vitry escribió un tratado, el Ars Nova, de donde el nombre de la nueva escuela, cuyo representante más conspicuo fue Guillaume de Machaut.

\section{El Ordo Missae y los textos de su Ordinarium}

Fue Guillaume quien de primero le puso música polifónica (a cuatro voces), en 1364, a un misa completa.

Es obvio que antes de escribirse misas polifónicas con textos en latín, se escribiera una inmensa cantidad de misas monofónicas en Gregoriano, de las cuales entresaco sólo los siguientes nombres: 


\section{Lux et origo. \\ Fons bonitatis. \\ De Angelis. \\ Cum jubilo. \\ Orbis factor,}

las misas más cantadas en el servicio litúrgico con música monódica.

Con Guillaume de Machaut, la misa en latín se va a constituir en el centro de la composición polifónica religiosa hasta la época actual. Existe una inmensa cantidad de misas, varias de ellas de excelente calidad musical. La Missa de Tournai, una recopilación de fragmentos anónimos del medio pontificio de Avignon, es otro de los primeros ejemplos musicales de misa.

Los textos de la misa generalmente son anónimos y su latín, aunque de la Edad Media, no se sale de los esquemas gramaticales tradicionales, que han sido transmitidos por la escuela desde el Tardío Imperio Romano, y musicalizado segun los distintos períodos de la música, las diferentes escuelas y sobre todo, el genio del compositor. La historia de la música, por más de mil años, ha sido la historia de la misa, pues ésta ha dominado el panorama musical hasta el presente. El género musical de la misa es mucho más antiguo que la suite, el concerto grosso, la sonata, la sinfonía, el concierto y la ópera...

Personalmente, no deja de llamarme la atención como genios de la música hayan echado mano de sencillos textos latinos medievales para componer sus grandes creaciones musicales y no de textos de los autores clásicos de la Antigüedad: Virgilio, Horacio, Catulo...

Etimológicamente, la palabra missa (voz pandiomática), procede de la fórmula religiosa Ite missa est!, ‘¡Idos, ya fue enviada!' (la Eucaristía a los enfermos, como último acto litúrgico) que se cantaba al final del oficio.

En su texto, la misa tuvo origen en las primeras centurias del cristianismo; se fue estableciendo de diferentes maneras y en distintos lugares y tiempos, hasta quedar fijada en un lapso que va del siglo IX al X. Ha estado conformada por tres partes esenciales: la Preeucaristía, la Eucaristía y la Posteucaristía:

La Preeucaristía:

Introitus, Kyrie (palabra griega), Gloria, Credo, Oratio, Epistula, Gradualis (Alleluia-Tractus), Sequentia, Evangelium y Credo.

La Eucaristía:

Offertorium, Secreta, Praefatium, Sanctus-Benedictus, Canon (palabra griega) Pater Noster, Agnus Dei y Communio.

La Posteucaristía:

Postcommunio, Ite, missa est, vel Benedicamus Domino.

También se da otra división, la que interesa en este trabajo:

el Ordinarium y el Proprium: 

variable.

El Proprium es lo que se reza, se lee o se canta en cada día festivo, como parte

El Ordinarium es lo común, lo corriente, lo ordinario, lo diario, pues se reza, o se canta en toda misa:

\section{Kyrie, Gloria, Credo, Sanctus, Benedictus y Agnus Dei.}

Y, aunque muchos compositores, en la historia de la música, hayan compuesto muchas partes del Proprium, por ejemplo, el más genial de todos ellos, W. A. Mozart, lo cierto es que en donde más han sobresalido es con el Ordinarium. Aquí la música desempeña un factor esencial; lo cual no sólo posee validez para el mismo Canto Gregoriano, sino también, y sobre todo, para la música de las misas polifónicas a partir de Guillaume de Machaut.

La misa constituye el centro de la liturgia romana y tanto en Gregoriano como en Polifonía, se da una simbiosis entre el texto idiomático y el texto musical. Así como no existe Gregoriano sin latín, tampoco existe polifonía ni contrapunto sin texto en latín en lo tocante a la misa tradicional, sólo con pocas excepciones; por ej., Franz Schubert con su Deutsche Messe(Misa en idioma alemán).

En conjunto, el Ordinarium posee un origen hímnico, al cual se le incorporan peticiones como el Kyrie o el Agnus Dei.

La I parte está así constituida:

\section{Kyrie eleison, Christe eleison, Kyrie eleison;}

triple petición en griego, lengua litúrgica anterior al latín como una alusión alegórica a la Trinitas.

Aunque no se canten en griego, el Gloria, Sanctus y Benedictus son también de procedencia helena, cuyas versiones en latín son de a partir del siglo VI.

La II parte es el Gloria, el Hymnus Angelicus; un texto amplio, de autor desconocido, estilísticamente simple, pero sentido, fervoroso y potente, aspectos casi siempre muy bien expresados en la música de los grandes maestros. Su construcción es paratáctica (oraciones yuxtapuestas), generalmente separadas por punto, en un latín provisto de semántica cristiana, en donde, otrosí, se hace alusión a la Trinitas Divina. El texto posee tres partes: una alabanza, peticiones y otra alabanza:

Gloria in excelsis Deo.

Et in terra pax hominibus

bonae voluntatis.

Laudamus te.

Benedicimus te.

Adoramus te.

Glorificamus te. 
Gratias agimus tibi propter magnam gloriam tuam.

Domine Deus, Rex calestis, Deus Pater omnipotens.

Domine Fili unigenite, Jesu Christe.

Domine Deus, Agnus Dei, Filius Patris.

Qui tollis peccata mundi, miserere nobis.

Qui tollis peccata mundi, suscipe deprecationem nostram.

Qui sedes ad dexteram Patris, miserer nobis.

Quoniam tu solus Sanctus.

Tu solus Dominus.

Tu solus Altissimus, Jesu Christe.

Cum Sancto Spiritu in gloria Dei Patris.

Amen.

Usualmente, el Gloria in excelsis Deo...es entonado, en Gregoriano, por el celebrante y, cuando hay schola cantorum por un solista, por lo general, tenor, seguido del coro.

La III. está conformada por el Credo, texto de mayor ampliación que el anterior; incluso, es el de mayor proporción en el Ordinarium. Una confesión o fórmula de fe, la cual sintetiza todo lo que el creyente debe creer. Contiene aspectos dogmáticos, históricos y la creencia en la resurrección futura. Este símbolo y confesión de fe fue aceptado por la Iglesia en el Concilio de Nicea (318) como dogma único contra Arrio, obispo de Alejandría, en cuya redacción desempeñó un papel importante Osio, obispo español (de la Baetica) a quien Constantino le había encargado disuadir a Arrio, quien se fundamentó en raíces helénicas y semitas para su negación de la Trinitas y de la Divinitas Christi.

En la misma Hispania, el Credo fue ampliado a partir del 589, fecha de la Abjuración de Recaredo, rey visigodo. Pero fue introducido en la misa hasta 1014, luego de una larga andada por Italia, Galia y España.

Estilísticamente, a no dudarlo, el Credo está escrito en buen latín, al menos, correcto. Toda la latinidad pagana del léxico tiene que ser convertido, semánticamente, en una latinidad cristiana, provista de hebraísmos y de algún que otro helenismo. Llama la atención, en muchos casos, el inicio de las oraciones con la conjunción et.

El Credo es entonado inmediatamente después del Evangelio, antes del Ofertorio. En muchas misas polifónicas, tampoco es extraño escuchar el inicio gregoriano, a veces desarrollado en forma multifacética, como en el Credo de la Misa en si menor de J.S. Bach.

Desde el punto de vista del dogma, el Credo es el símbolo de la fe, de la unidad y cántico universal: un Dios único para todos, única su Iglesia, única la vida futura. Históricamente, trae a la mente el desvanecido sueño imperial de la Roma antigua de un único imperio para todos.

La IV., el Sanctus, es la conclusión del Praefatium: 
Et ideo cum Angelis et Archangelis, cum Thronis et Dominationibus cumque omni militia caelestis exercitus hymnum gloriae tuae canimus sine fine dicentes:

"Sanctus, Sanctus, Sanctus Dominus, Deus Sabaoth. Pleni sunt caeli et terra gloria tua. Hosanna in excelsis".

Inmediatamente, sigue la conclusión del Praefatium, con la $\mathrm{V}$ parte: el

\section{Benedictus, qui venit in nomine Domini.} Hosanna in excelsis.

Desde el I. Sanctus al gloria tua ha sido extraído de la liturgia judía y el Hosanna in excelsis procede de San Mateo.

En el Sanctus, el oficiante y el pueblo junto con todo el ejército celestial cantan al Creador. En esta parte de la misa, generalmente, los compositores impregnan la música de gran solemnidad.

La V., el Agnus Dei procede de un ritual del este europeo, introducido en la misa por el Papa Sergio I, en 701. También, como en el Kyrie y en el Sanctus, se da una triple invocación: en las dos primeras: misere nobis; en la última: dona nobis pacem.

La música eclesiástico-litúrgica de la Roma occidental, desde antes del Canto Gregoriano, está muy asociada con el latín, aunque, acá y acullá, los textos presenten algunos helenismos; por ejemplo, en el Ordinarium, los siguientes: Kyrie eleison, Christe eleison, Prophetas, Catholicam, Ecclesiam y Baptisma; y los siguientes hebraísmos: Jesus, Maria, Sabaoth, Allelluia, Hosanna y Amen.

\section{Misas de la Escuela Franco-Belga}

Los siglos XIV y XV están dominados por la música Franco-Flamenca (de Flandes) o Franco-Belga. Es una música solemne y llena de colorido, en donde descuella la polifonía religiosa de carácter vistuosístico, muchas veces, a partir de un Cantus Firmus: tema ya existente, generalmente, gregoriano.

En el Ducado de Borgoña, sobresalió la Ciudad de Cambrai en las cortes de Felipe el Bueno y de Carlos el Temerario, en donde brilló el lujo, la magnificencia, el esplendor y la belleza, que hicieron, que, en la esfera musical, se creara un arte refinado, casi perfecto en su técnica, también de colorido y esplendor. La música actúa como un medio de purificación del espíritu, allá en una región limítrofe entre Bélgica y Francia.

Compositores de tal escuela son: Ockeghem con su Missa mi-mi y el canon Deo gratias (a 36 voces); Obrecht y Heinrich Isaac: un Proprium denominado Chora- 
lis constantinus, originalmente, Choralis Constantiniensis (Coral de Constanza), un ciclo anual, pero sin gradualis ni offertorium. Los más sobresalientes son Guillaume Dufay (ca. 1400-1474) y Josquin des Prez (Ca. 1440-1521).

Dufay, entre otras, escribió:

\title{
Missa Ecce ancilla Domini. Missa Sine nomine,
}

(cuando la misa no se basaba sobre un cantus firmus, pues el tema era original del mismo compositor).

\section{Missa Sancti Jacobi;}

además de motetes e himnos. Josquin, máximo representante de la escuela Franco-Flamenca, compuso, entre otras:

\section{Missa Hercules, dux Ferrariae. Missa De Beata Virgine. Missa Ave maris stella,}

ésta sobre el tema gregoriano:

\author{
Ave maris stella, \\ Dei mater alma, \\ Atque semper virgo, \\ Felix coeli porta...
}

Luego el coro, sobre variaciones del gregoriano, desarrolla la misa en polifonía.

\section{La doble vía musical en el Renacimiento}

¡Con la polifonía renacimental se adentra en los umbrales de la música moderna! Durante el Renacimiento italiano, sobre todo, con el Humanismo se da un cambio de brújula: se acentúa la división entre la tierra y el cielo; entre lo mundado y lo religioso. El ser humano se siente ahora más libre, pues cree en su razón: ¡todo lo somete a juicio! El disfrute de la vida, de la naturaleza, del arte... engendra en él otras actitudes: más confianza en sí mismo, menos pesimismo y menos obediencia a la Iglesia; en todo caso, más espíritu crítico.

Los humanistas no quieren tener que vérselas con el latín medieval y se aferran al latín ciceroniano; pero, por ironías del destino, éste pierde su exclusividad; tiene ahora buenos contrincantes: ¡las lenguas nacionales: románicas y germánicas! 
En la esfera musical, los polifonistas siguen dos vías: la música seglar, para disfrute del arte por el arte y la música religiosa, para ser ejecutada en los templos. La primera, sin excluir el latín, es en romance; la segunda, en latín.

De los textos medievales se siguen usando, principalmente, los de la misa.

En Chartres nace Antoine Brumel, quien compone una misa a 12 voces Et ecce terrae motus y un Dies irae, en donde se palpa la voz angustiosa de los trombones y del coro por el fin del mundo. Pierre de la Rue escribe una Missa pro defunctis. William Byrd, compositor inglés posee una misa para tres voces. Por la misma época, Jacobus Gallus escribió la Missa ad imitationem Pater Noster, para ocho voces para doble coro.

\section{Música en latín de la Escuela de Venecia}

En la esfera musical, el Renacimiento de Italia es también esplendoroso, a lo cual contribuyó, en gran medida, la Escuela de Flandres, con el movimiento musical que se inicia en la espléndida y dorada Catedral de San Marcos, Venecia, en donde, a finales del $\mathrm{XIV}$, se habían escrito canciones con textos en latín: la canción polifónica. A pesar de que en la Ciudad Adriática los compositores escriben una música instrumental solemne, grandiosa, no se descuida la música coral: Wallaert, puente con la música de Flandes, combina motetes, psalmos y canzoni villaenesche con misas. Andrea Gabrieli combina lo sagrado con lo profano: Sacrae cantiones (a cinco voces, 1565) y las Ecclesiasticae cantiones (a cuatro voces). Su labor musical es continuada por su sobrino, Giovanni Gabrieli, quien, entre otras composiciones, posee una colección de motetes, un Kyrie, un Magnificat, un Sanctus, Letaniae. De un gran sentimiento, grandeza y devoción es su motete:

\section{Dulcis Jesu, patris imago et salus nostra, qui morte crucis nos omnes redemisti. Libera nos, protege nos ab omni malo, ut digni reperiamus esse in coelis.}

Además de su excelente

Audite principes, et auribus percipite omnes habitationes terrae.

Et exultate.

Audite, senes, quae loquor vobis:

y de audiat terra verba oris mei in laetitia...

Quem vidistis pastores?

O Jesu dulcissime. 


\section{Jubilate Deo. In ecclesiis. \\ Timor et tremor. \\ O magnum mysterium.}

textos con música religiosa muy solemne y sentida, así, al estilo de G. Gabrieli.

En los siglos XV y XVI, a la música religiosa en latín se le agrega il madrigale italiano, género secular: un motete profano.

En la escena musical, todos también con composiciones en latín, aparecen $\mathrm{Pa}$ lestrina, Monteverdi, quien también escribió misas, el Vespro della Beata Vergine (1610), una serie de psalmos y concerti, en latín, además de sus dos Magnificat y el himno Ave maris stella, de tanta belleza y solemnidad; y Roland Lettré, alias Orlando di Lasso, el cual compuso 50 misas. ¡Palestrina, Monteverdi, G. Gabrieli y Orlando di Lasso son verdaderos maestros de la música, y no sólo del Renacimiento!...

El siguiente madrigal, como proceso de secularización, es de Orlando di Lasso, el último y el más grande representante de la Escuela de Flandes, gran parte de su vida transcurrida en el centro de Munich:

\section{Praesidiumn Sara, dulce meum decus atque voluptas, curarum requies delitiaeque meae, in cuius spero idalias compescere flammas aligerique Dei vincere tela sinu, laetemur gratesque Deo, mea sponsa, tonanti persolvamus. Io, lux genialis adest, ut modocontractum solita pietate fecundet coniugium aeterna detque quiete fini.}

\section{Palestrina o el Estilo Romano, en latín, y la Reforma Luterana}

Durante la Contrarreforma, la música religiosa en latín cobra vida, en contraposición con la música, en alemán, una consecuencia del Luteranismo.

La música religiosa polifónica de Palestrina es bien vista y aplaudida por el Concilio de Trento, gracias a su excelente Missa Papae Marcelli (1565), por la cual evitó el destierro de la música polifónica del rito católico. Il maestro di San Pietro compuso misas, motetes e himnos. El Estilo de Palestrina genera un modelo ideal de contrapunto, el cual es imitado en España por Cristóbal Morales y T. L. de Victoria, quienes escribieron música sacra.

Victoria escribió misas polifónicas 'a cappella', por ejemplo:

Missa $\mathrm{O}$ magnum mysterium.

Missa O quam gloriosum. 
Algunos nombres de misas de Palestrina, entre las 93 que compuso, son:

\author{
Missa brevis \\ Missa Aeterna Christi munera. \\ Missa Nigra sum. \\ Missa Ecce ego Johannes. \\ Missa Sine nomine. Missa brevis. \\ Missa Tu es Petrus \\ Missa Assumpta est Maria,...
}

A la escuela de Palestrina pertenecen Felice Arnerio con su Venite ad me omnes; Giovanni B. Nanino, con Haec dies, Ruggiero Giovanelli, con el Jubilate Deo y Gregorio Allegri con su indirectamente famoso Misere.

Anteriormente, en Germania, un exmonje augustino había traducido la Biblia al alemán, crea y fomenta himnos y corales en este idioma para el servicio religioso, cantados por el mismo pueblo. El antirromanismo luterano lleva a desterrar el latín del culto, no así de la vida académica. No obstante, $H$. Schütz compone motetes en latín, sus Cantiones Sacrae y J. S. Bach, su Misa en si bemol.

Se dan unos pocos casos en que compositores hacen música echando mano a textos de autores clásicos, como el Dulces exviae... de Virgilio, o el Beatus ille..., de Horacio. De éste existe un Horatius Decantatus: siete odas cantadas en latín, cuyos compositores, desde un anónimo del siglo X a uno de 1935. Orlando di Lasso y Z. Kodály están incluidos en la colección.

¡He aquí las odas del disco!:

\title{
Donec gratus eram tibi... \\ Albi, ne doleas... \\ Integer vitae... \\ Vides ut alta stet... \\ Nunc est bibendum... \\ Rectius vives... \\ Exegi monumentum...
}

¡Y los dos épodos!:

\section{Altera iam bellis... Beati ille...}

No obstante el proceso de secularización y deslatinización de la música...

De facto, la composición de Virgilio y las odas y épodos de Horacio, constituyen, naturalmente, una secularización, pues no es música nacida en el seno eclesiástico. 
Además del luteranismo alemán, el cual causa que gran parte de Alemania se desate de los vínculos de Roma, y la creación de los modernos estados europeos, ya con sus idiomas nacionales, en 1600 aparece la ópera en Florencia; se da un mayor proceso de secularización de la cultura como consecuencia de la imprenta; alcanzan gran esplendor las distintas cortes y salones de gente noble y se comienza a hacer mayor uso de los instrumentos musicales; en contraste con la polifonía coral y, por supuesto en italiano, se comienza a desarrollar el área solista de difícil ejecución, todo lo cual conlleva a que el uso del latín se haga más esporádico, al menos entre la gente de menor cultura, a pesar del Humanismo-Renacimiento. Con todo, no desaparece, pues las composiciones religiosas, grandes obras, sobre todo misas, siguen empleando el idioma de la Roma, con lo cual, éste no sufre del todo mengua.

Genios de la música, por razones que no vienen al caso examinar aquí, no desisten de componer música vocal-coral con textos en latín, no obstante la ópera en italiano. ¡Las misas siguen descollando!. Es una música inspirada, muy devota, en nada indigna de otras obras musicales.

\section{Misas y obras en latín de genios de la música}

No obstante el luteranismo, una gran parte de Alemania y toda Austria permanecen fieles a Roma. Incluso, J. S. Bach y G. F. Händel componen algunas obras en latín; aunque hayan escrito la mayoría de sus obras cantadas, respectivamente en alemán y en inglés, como las cantates y las pasiones del primero, o el Mesías y el magnífco Te Deum de Dettingen del segundo. Bach escribió un Magnificat, y Händel, un Laudate pueri, un Nisi Dominus y una Salve Regina.

Las misas de Haydn y de Mozart tuvieron antecedentes en Alessandro Grandi y en Tarquino Merula; en parte continúan el antiguo estilo contrapuntístico, con coros y solistas en forma ocasional.

En Roma, aparece un estilo policoral monumental en oposición al precedente: Orazio Benevoli (1628) compone una misa festiva para la inauguración de la catedral de la ciudad de Mozart: dos coros de ocho voces se las tienen que ver con seis coros de instrumentos en un stylus mixtus: elementos polifónicos con elementos concertantes homófonos. En Italia un genio prolífico, además de otra clase de música religiosa:

Stabat mater...

Nisi Dominus...

Laudate pueri...

Laudate Dominum...

Dixis Dominus...

Magnificat...

Beatus vir... 


\section{Credidi porpter quod... \\ Laetatus sum... \\ Domine ad adjuvandum me... \\ Sacrum...,}

escribe música para la misa, en donde sobresale su Gloria. Él mismo era sacerdote ("il Prete rosso") Antonio Vivaldi.

Otros compositores alemanes de misas del siglo XVIII, aunque menos conocidos, son:

Johann H. Schmeltzer, Heinrich Franz Biber, J. Kaspar Kerl y Johann Joseph Fux, creador del ofertorio

\section{Plaudite, sonat tuba \\ ad gaudia, o gentes...}

En Italia, también se dio la Escuela Napolitana, la cual contribuyó, otrosí, con misas, en donde se destacan, claro está, las arias: Alessandro Scarlatti, Leonardo Vinci, Leonardo Leo, Fco. Durante. Todos éstos escribieron misas con arias, coros, duetos. El joven Pergolesi impregna sus misas con las conquistas de la ópera. También son notables las misas escritas por Niccolo Jomelli, Antonio Lotti y Antonio Caldara, compositor veneciano de la Capilla Imperial de Viena y autor de la Missa Laetare, para in festo S. Matthiae Apostoli, o si no para In festo S. Josephi sponsi B. M. V., et Patroni Austriaci. Las misas de los compositores anteriores están impregnadas de un cierto espíritu operístico.

Johann S. Bach también es grandioso con su Misa en si menor, en donde combina distintos elementos musicales: arias, coros, solistas vocales e instrumentales, grandes masas corales y orquestales en una gran solemnidad, hábil desarrollo y alegría desbordante. El inicio del Credo in unum Deum..., a siete voces, se desarrolla a partir de la respectiva melodía gregoriana.

Sus hijos y su contemporáneo, D. Buxtehude, también escribieron obras en latín.

Las 15 misas de J. Haydn no se siguen un esquema uniforme, sobre todo, las seis últimas. Este compositor austríaco compuso, entre otras, las siguientes

Missa de armonia.

Missa de creatione.

Missa in angustiis (Misa Nelson).

Missa in tempore belli.

Missa in honorem B. V. M.

Missa sancta.

Missa de sancta Caecilia.

Missa Sancti Joannis de Deo.

Missa de sancta Teresa,... 
aunque también compuso, en alemán, a imitación de Händel, un oratorio, Die Schöpfung, 'La Creación'.

W. A. Mozart escribió unas 15 misas: Missae breves y Missae solemnes. La missa brevis es ajustada y sencilla: un coro pequeño es acompañado por una orquesta casi sólo de cuerdas. La missa solemnis posee mayor amplitud temporal y cuantitativa: a las cuerdas se agregan flautas, oboes, trompetas, timbales y a veces, hasta órgano, como en la culminación mozartiana, la Grosse Messe, inconclusa, y en su Requiem, de gran estilo, arias exuberantes de coloratura; pero la misa más conocida, por ser de mayor ejecución, es la Misa de Coronación. W.A. Mozart escribió una Missa Solemnis cuando se encontraba en en el proceso de cambio de la niñez a la juventud, la Waisenhausemesse, así, en un "estilo muy mozartiano"... Otra Missa solemnis del Salisburgues es la que lleva el número 337 del catálogo $\mathrm{K}$.

Mas el Genio de Salzburgo no se contentó sólo con el Ordinarium, pues también tiene muchas joyas para otras ocasiones del rito romano:

\author{
Antiphonae. \\ Regina coeli. \\ Offertorium. \\ Vesperae solemnes de confessore. \\ Laudati pueri. \\ Laudate dominum. \\ Venite populi. \\ Misericordias Domini. \\ Exultate, jubilate. \\ Inter natos mulierum. \\ Sancta Maria, mater Dei \\ Vesperae de Domenica...
}

Su obra religiosa, en pequeño, más cantada, es el motete de la festividad del Corpus Christi (K. 618, del 17 de junio de 1791), el:

Ave verum corpus,

natum de Maria virgine, vere passum, immolatum in cruce pro homine; cujus latus perforatum unda fluxit et sanguine. Esto nobis praegustatum in mortis examine; 
en un movimiento lento, piadoso y mejestuoso... genial, como todo lo salido del alma, corazón y pluma del Niño prodigio.

El otro genio, el de Bonn, con su Missa Solemnis amerita mención. Beethoven es grandioso no sólo por sus sinfonías, oberturas, conciertos, sonatas y cuartetos, sino también por esta misa: extensa, con una gran masa coral y orquestal, arias de difícil interpretación y partes contrapuntísticas, en donde todos los ejecutantes: orquesta, coro y solistas, están sometidos a grandes exigencias técnicas, en una obra no indigna de la $I X$ Sinfonía, ambas compuestas casi con el mismo opus. La Missa Solemnis de Beethoven, más que de catedral, es un composición de sala de conciertos. Futwängler dijo de ella que era una sinfonía con palabras.

En Austria apareció otro genio de la música que recogió, románticamente, la herencia de la Escuela Vienesa: Franz Schubert les proporciona a sus misas coloratura armónica. Notables son la Misa en la bemol mayor y la Misa en mi bemol mayor, de hábil elaboración estilística.

Posteriormente no se apagó el gusto e interés por seguir escribendo misas con los tradicionales textos en latín. Sólo menciono los nombres de:

Cherubini, Weber, Rossini, Liszt, Bruckner, Berlioz, Gounod y la misa, de 1948 , de Igor Stravinsky, con acompañamiento de instrumentos de viento, la cual, en parte, se entronca con la primera misa, la de Guillaume de Machaut, en plena Edad Media.

Finalmente existen algunas breves composiciones religiosas en latín, especie de motetes, bastante recientes y conocidas, como el:

\author{
Transeamus usque Bethlehem..., \\ de Schnabel. \\ Ave Maria... \\ de Schubert, Bach-Gounod, Bruckner. \\ Agnus Dei..., \\ de Bizet, \\ y Panis Angelicus..., \\ de Cesar Frank.
}

\title{
Resumen conclusivo
}

En sencillos y simples textos como son los de la Misa de la Iglesia Romana y en otras composiciones de carácter religioso, se esconden gigantes de la música, por lo cual la tradición del latín ha continuado inundando la cultura de Occidente. El hecho en sí podría pasar inadvertido, pero es que ellos, los más excelsos compositores de la música occidental, algunos apenas nombrados en este opúsculo, no desdeñaron ni se avergonzaron de seguir usando la lengua universal de la cultura en sustitución de su respetiva lengua nacional. 
En la época del período del latín clásico, el Siglo de Augusto, no existía todavía lo que hoy se entiende por música clásica; de hecho, de la música romana no se conoce casi nada; lo más antiguo conocido es el Canto Gregoriano, del cual se derivan otros movimientos musicales: los poetas trovadores impregnan su música, simple y monódica, de poesía en romance; con el Ars Antiqua y el Ars Nova se inicia la música polifónica. En el Renacimiento, la música, tanto en latín como en romance; religiosa o secular, es de carácter muy culto; en el Preclasicismo, Clasicismo y Romanticismo, se producen obras musicales de gran envergadura, muchas de ellas en latín, en donde sobresale la misa.

La contribución de Roma y del latín, en este caso postcristianos, en el origen y desarrollo de la música son fundamentales, como en tantos otros campos, sobre todo, del arte... Fehacientemente se deja ver en este artículo cómo la Edad Media fue un período, en que, a pesar de todo tipo de adversidades, hubo seres humanos capaces de sobreponenerse a ellas y crear aspectos culturales que han sobrevivido hasta el presente, como en el caso de la música, arte que tampoco ha podido prescindir de la benéfica influencia del latín.

En fin, hay tanta y tan bella música compuesta sobre textos en latín que este mi trabajo constituye apenas un esbozo introductorio del empleo del latín en la historia de la música...

\section{Bibliografía}

Alberti L. 1968. Musica nei secoli. Milano. Arnoldo Mondadori Editore -CEAM-.

Carmina Burana. Die Lieder der Benedikbeurer Handschrift. Dünndruck-Ausgabe. dtv klassik.

Curtius Ernst, Robert. Literatura europea y Edad Media latina. México: Fondo de Cultura Económica.

Della Corte y Gatti. 1949. Diccionario de la música. Buenos Aires:Ricordi Americana.

Finney, Theodoro M. 1935. A History of Music. New York: Harcourt, Brace and Company.

Fratelli Fabbri Editori. 1964. Storia della musica. Milano.

Herrero, Víctor J. 1965. Introducción al estudio de la filología latina. Madrid: Editorial Gredos.

Lang, Paul Henry \& Bettmann Otto. 1961. A Pictorial History of Music. Nueva York: Nortor \& Company, Inc. 
Maurice, Emmanuel. 1935. L' initiation a la musique. París: Editions du Tambourinaire. Missale Romanum. Editio XXVII juxta typicam vaticanam, Ratisbonae, sumptibus et typis Friderici Pustet.

Moreno Jesús, Peira Pedro. 1979. Crestomatía Románica Medieval. Madrid: Cátedra.

Nestler,Gerhard. 1965. Geschichte der Musik, Europaïsche Bildungsgemeinschaft. C. Gütersloh: Bertelmann Verlag .

O. Blochet, Wartburg W. V.1964. Dictionnaire étymologique de la langue française. París: Presses Universitaires de France.

Panosfsky, W.1964. También tú sabes de música. Barcelona:Editorial Labor S. A.

Prampolini, Santiago. Historia Universal de la Literatura.V. III. México: UTEHA.

Quirós R., Manuel Antonio. 1994. “1492: Humanismo y Renacimiento en España”. Káñina, Revista de Artes y Letras de la Universidad de Costa Rica. 18 (I): 209-217.

Riquer, Martín de. Los Trovadores. Historia literaria y textos. Barcelona: Editorial Planeta.

Siegel, Conrad. 1960. Gramática latina. Buenos Aires: Editorial Guadalupe.

Segura Mungía, Santiago. 1985. Diccionario etimológico latino-español. Madrid: Ediciones Generales ANAYA.

Stephen Rudolf, Música. 1964. Enciclopedia moderna del conocimiento universal. Buenos Aires: Compañia General Febril Editor.

Schnoor, Hans. Oper, Operette, Konzert. Gütersloh: Bertelsmann Ratgeberverlag, Reihard Mohn OHG.

Wangermée, Robert. 1975. La musique flamande dans la société des XV. et Xve. siecles. Bruselas: Éditions Arcade.

Wright, Roger. 1982. Late Latin and early Romance in Spain and Carolingian France. Liverpool: Francis Cairns.

Yudkin, Jeremy. n.d. Music in Medieval Europe. Nueva Jersey: Prentice Hall. 